RADIO WAVE PROPAGATION 
Philips Technical Library

\section{RADIO WAVE PROPAGATION}

ARMEL PICQUENARD 
ISBN 978-1-349-01396-8 ISBN 978-1-349-01394-4 (eBook)

DOI 10.1007/978-1-349-01394-4

English edition (C) N.V. Philips' Gloeilampenfabrieken, Eindhoven, 1974 Softcover reprint of the hardcover 1st edition 1974 978-0-333-13312-5

All rights reserved. No part of this publication may be reproduced or transmitted, in any form or by any means, without permission

SBN 333133129

First published 1974 by

THE MACMILLAN PRESS LTD

London and Basingstoke

Associated companies in New York Melbourne

Dublin Johannesburg and Madras

Library of Congress

Catalog No: 72-2046

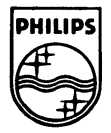

PHILIPS

Trademarks of N.V. Philips' Gloeilampenfabrieken 


\section{CONTENTS}

Introduction 1

Chapter 1 Propagation of radio waves in a dielectric 3

1.1 Propagation of plane waves 3

1.2 Spherical waves 8

$\begin{array}{ll}\text { Chapter } 2 \text { Tropospheric propagation } & 13\end{array}$

2.1 Propagation in a standard atmosphere 13

2.2 Propagation in a stratified atmosphere 21

2.3 Tropospheric scattering 29

Chapter 3 Wave propagation in the ground $\quad 54$

3.1 Terrestrial electric constants 54

3.2 Electrical behaviour of imperfectly conducting bodies 54

3.3 Propagation of a plane sinusoidal wave of constant frequency in an imperfectly conducting medium 55

3.4 Wave propagation in the ground 58

Chapter 4 Wave propagation close to the earth's surface 59

4.1 Wave reflection from the earth's surface 59

4.2 Wave behaviour near the ground 71

4.3 Field value on flat ground; surface wave 74

4.4 Calculating the field on spherical ground 78

4.5 Propagation over irregular terrain 80

Chapter 5 Wave propagation in ionized media 86

5.1 Constitution of an ionized medium 86

5.2 Motion of particles; effect of electric and magnetic fields $\quad 87$

5.3 Propagation in the absence of a magnetic field 90 
5.4 Propagation in the presence of the earth's magnetic field, when the latter is parallel to the direction of propagation

5.5 Complete equation and approximations $\quad 100$

$\begin{array}{lll}\text { Chapter } 6 \text { Ionospheric propagation } & 102\end{array}$

6.1 The ionosphere 102

6.2 Ionospheric propagation $\quad 125$

6.3 Ionospheric predictions 149

6.4 Random variations in the ionosphere 151

Chapter 7 Principles of calculating a radio link 158

7.1 Field received 158

$\begin{array}{ll}7.2 \text { Field required } & 170\end{array}$

7.3 Calculating the minimum required field 183

Chapter 8 Practical calculation of radio links 184

8.1 Introduction 184

8.2 Decametric (h.f.) and longer waves 186

8.3 Metre and shorter waves 274

Appendices $\quad 303$

A.1 Units 303

A.2 Properties of electromagnetic fields 305

A.3 Maxwell's equations 306

A.4 Retarded potentials 308

A.5 Hertzian vector 309

A.6 Statistical distributions $\quad 310$

A.7 Fourier transformations $\quad 320$

A.8 Fresnel zones 322

A.9 Doppler effect 325

A.10 Calculation of the signal-to-noise ratio 326

References 331

$\begin{array}{ll}\text { Index } & 341\end{array}$ 